
Magdalena STĂNCULESCU

Situl și clădirea teatrului, prin arta

teatrului, oferă reciproc noi

semnificații

The site and the theatre building,

through the art of theater,

reciprocally provide new meanings

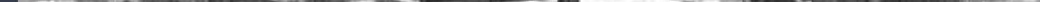




\section{Situl și clădirea teatrului, prin arta teatrului, oferă reciproc noi semnificații}

The site and the theatre building, through the art of theater, reciprocally provide new meanings

\section{Magdalena STĂNCULESCU}

magda_stanculescu@yahoo.com

Conf. Dr.Arhitect, Director SP*, FA UAUIM Assoc.Prof. Dr.Architect, Director SP*, FA UAUIM

*Departament Sinteza Proiectării de Arhitectură Facultatea de Arhitectură
Universitatea de Arhitectură și Urbanism lon Mincu UAUIM București *Synthesis of Architectural Design Department (SP) Faculty of Architecture Ion Mincu University of Architecture and Urbanism UAUIM Bucharest
În această lucrare de poziționare (profesională), voi încerca să surprind substanța dezvoltării spațiului public, alăturată sau vecină, indusă la inserarea sau re-funcționalizarea spațiilor de teatru contemporane.

Printr-o scurtă prezentare comparativă a unor exemple remarcabile de practică internațională a intervențiilor similare în zonele urbane, voi încerca să surprind tendințele și direcțiile de revitalizare și dezvoltare ale unor astfel de zone, ca spații civice cu multiple atractii - culturale si publice. Aceste exemple sunt narațiuni ale posibilitătilor urbane care ar oferi oportunități de evadare, experimentare, interferență cu ceilalți, relaționare cu natura și deschidere spre diversitate. Fie că este vorba despre situri istorice, afectate de intervenții ulterioare, situri cu personalitate bine definită - ambientală sau stilistică, sau situri complet distruse, planificarea urbanistică a acestor spații ar trebui să ia în considerare un cadru adecvat pentru a asigura identitatea locală, sentimentul de apartenentă la un anumit loc și adaptarea la actualitate. Din 1989, toate investițiile în artă și cultură au fost doar sporadice, bazate pe intervenții private care au implicat fonduri limitate. În ceea ce privește clădirile și spațiile de teatru a existat o intervenție remarcabilă de consolidare, remodelare și reconfigurare la cel mai semnificativ exemplu de România Teatrul Național București (T.N.B.). Această prezentare este axată pe propunerile și ideile îndrăznețe privind spațiul existent construit, dar marcând și influența asupra spațiilor publice urbane adiacente sau învecinate. Intervenția urbană, precum și cea funcțională trebuie să fie echilibrate cu atenție, astfel încât concluziile traduse în spații arhitecturale, reprezentând intervenții importante ale orașului pe o mare unitate de timp, să fie opțiunea corectă și profund profesională. Accentul este pus pe continuitatea tradițiilor culturale printr-o transformare permanentă, prin asimilarea noului, presupunând că un mod puternic de funcționare - ținând cont de zona înconjurătoare - și rescrierea sau reinterpretarea acesteia. Aceste tipuri de intervenție implică o colaborare strânsă a unei echipe multidisciplinare, pentru a strânge și organiza informații, conducând la decodificarea zonei de studiu, pentru a realiza o strategie de conectare a sitului social și urban adiacent zonei. Această lucrare oferă un punct de plecare pentru potențiali investitori, dar și pentru administrația publică, din dorința de a crea parteneriate care să asigure o mai bună cooperare. cuvinte cheie

clădiri și spații de teatru, spații publice urbane, crearea de noi atracții publice abstract

In this position paper I am trying to capture the substance of public space development, adjoining or neighboring, induced to the insertion or re-functionalization in contemporary theatre spaces.

By a brief comparative presentation with a few outstanding examples of international practice of similar interventions in urban areas, I seek to capture the trends and directions for the revitalization and development of such areas, as civic spaces with multiple - cultural and public - attractions. These examples are 位 to escape, experiment, interfering with others, relate with nature and open to diversity. Whether it's about historical sites, affected by subsequent interventions, sites with well-defined personality ambient or stylistic, or completely destructured sites, urban planning of these spaces should consider a proper framework to ensure local identity, the sense of belonging at a certain place and adapted to the current century. Since 1989, all investments in art and culture were only sporadic, based on private interventions involving limited funds. Regarding theater buildings and spaces there has been a remarkable intervention of consolidation remodeling and reconfiguration at the most significant example of Romania - Bucharest National Theatre (T.N.B.). This presentation is focused on the proposals and bold ideas concerning the existing space built, but also marking the influence on urban public spaces adjoining or neighboring. The urban as well as the functional intervention should be balanced carefully, so that the conclusions translated into architectural spaces, representing important city interventions on a large unit of time, be the right and deeply professional option. Emphasis is given to the continuity of cultural traditions by a permanent transformation, by assimilating the new, supposing that a strong mode of operation - taking into account the surrounding area- and rewrite or reinterpret it. These types of intervention implicate close collaboration of a multidisciplinary team, to gather and organize information leading to decoding the study area, to achieve a strategy for connecting social and urban site adjacent to the area. This paper provides a starting point for potential investors but also for public administration in the desire to create partnerships that provide better cooperation.

keywords

theatre buildings and spaces, urban public spaces, create new public attractions. 


\section{Introducere - semnificația subiectului}

Provocate de un context urban din ce în ce mai complex, clădirile de teatru trebuie să-și integreze designul în țesutul urban existent printr-o interpretare abilă și sensibilă a scopului clădirilor și a relației cu publicul. În loc să îndeplinească doar un scop estetic, designul proiectelor de astăzi are o importanță culturală, politică și socială, și doar cele care reușesc să reflecte aceste valori, în combinație $\mathrm{cu}$ o abordare nouă a practicii arhitecturii, pot fi considerate spectaculoase. Tinând cont de aceste aspecte și criterii, prezentul studiu oferă unele dintre cele mai noi cerințe practice, pentru eventualele investiții ulterioare în arhitectura teatrului, fie private, publice sau mixte și expun o ilustrare a procesului de materializare a ideii, a conceptului de conexiune între clădirea arhitecturală și spațiul public. Această lucrare intenționează să fie un suport de documentare pentru oricine dorește să acceseze acele idei inovatoare (de asemenea, pentru studenții arhitecți), în timpul în care gândirea și proiectarea unei clădiri de teatru se schimbă constant (re-gândirea arhitecturii prin redefinire). Ideea principală urmată este: necesitatea redefinirii continue a proiectării de spații și clădiri de teatru este singura cale de a realiza proliferarea acestui tip de arhitectură. Aceasta necesită cunoștințe solide despre trecut, chiar și imediat, de la care învățăm și ne inspirăm constant, pentru a fi pregătiți pentru viitor. Totul este privit într-o perspectivă nouă, reorganizată, întorcându-ne întotdeauna la termeni precum: procese de dezvoltare, variabilitate, libertate de exprimare, simplitate și esențialitate a spațiului și a echipamentelor, reducere a costurilor de investiții și operare, capacitate de adaptare în timp, utilizare intensivă a spațiului. În prezent, tipurile de activități desfăsurate în aceste clădiri pot fi modificate, sunt în continuă schimbare, programele sunt agregate și devin mai complexe sau, dimpotrivă, tind către o „sărăcie” și simplificare, astfel încât arhitectul se confruntă permanent cu no circumstanțe. Cunoștințele pe care acesta le-a dobândit treptat au cerut timp pentru experimentare și perfecționare. $O$ singură persoan nu mai deține toate aceste date, corelate cu detalii cu criteriile urbane și criteriile de management, încheiate $\mathrm{cu}$ o nouă abordare: echipe multidisciplinare de specialiști. Pe de altă parte, în dezvoltarea orașului contemporan se generează zone neutilizate, uitate, fracturate, care devin adevărate bariere în teritoriu, goluri funcționale, chiar dacă acestea sunt situate aproape de zona centrală. Astăzi, domeniul spațiului urban public, conține încă spații neutilizate, adecvate pentru refunctionare. Studiul contine un întreg complex de întrebări, îndoieli și contradicții, care sunt specifice pentru un organism la fel de complex și permanent viu precum spațiul urban. Încerc să subliniez ideea de a cuceri noi locuri de relaxare și de interconectare cu orașul, prin dezvoltarea de spații publice urbane în imediata apropiere a clădirilor culturale [1].

\section{Metodologie}

Ca o consecintă a evoluției generale, asistăm astăzı la o schimbare a atitudinii filozofice și acceptarea ideilor de schimbare continuă, studiul zonelor de frontieră, adevăruri relative, o nouă atitudine despre valori (acceptarea valorilor care provin din diferite culturi, repunerea în discuție a nevoilor umane) și întoarcerea atenției asupra persoanei, beneficiarului sau utilizatorului arhitecturii. Arhitectura tinde să rezolve problemele comunităților, ale grupurilor, să accepte diferențele culturale și marchează importanța emoțiilor și percepțiilor umane. Cum putem face asta? Potrivit lui Bruno Zevi: „viața s-a descompus întotdeauna, s-a articulat, s-a adăugat și nu s-a remodelat" [2]. Așadar, pe baza acestei afirmații, am fost inspirată să folosesc metodologia 
inventarului ca o condiție anterioară: „Inventar înseamnă a clarifica semantica. Nu am folosit cuvinte înainte de a analiza conținutul lor profund "[3]. Această metodă de descompunere în activități, criterii sau idei separate este urmată de o metodă de inventar și apoi se recompune urmând principiul reintegrării. Pentru a realiza un model care să mimeze realitatea, trebuie să ținem cont și de aspectul timpului. Louis Kahn ne indică necesitatea de a stabili diferența dintre spațiile pentru parcurs și spațiile pentru ședere: „spațiul trebuie să fie trăit, folosit social, capabil să primească și să sublinieze valoarea evenimentelor" [4]. Principalele metode includ cercetare documentară, date statistice și interviuri semi-structurate cu angajații și managerii activităților creative și membri ai personalului tehnic al autorităților locale. Prin aplicarea metodelor de cercetare calitativă și a observației arhitecturale, ca parte a proceselor de reînnoire urbană, poate deveni un mijloc de a construi o relație continuă și directă între teritoriu, părțile interesate, instituțiile și cetățenii. De asemenea, folosesc metoda de cercetare a ritmului, prin care compar și contrastez viața socială asociată în spațiile publice legate de clădirile de teatru.

\section{Cercetări pentru exemple}

Există deja un număr mare de realizări spectaculoase în clădirile de teatru, care surprind prin îndrăzneală, performanță și modul în care răspund cerintelor funcționale și estetice. Următoarele proiecte prezentate sunt analizate și ilustrate pentru motivul efervescenței lor asidue pentru a căuta identitatea conceptuală și formală legată de spațiul public. Invadate de energie pozitivă, proiectele reflectă o viziune tinerească a gândirii, o nouă modalitate de umplere a spațiului deasupra și în subteran, implicarea socială a cetățenilor și abordarea conceptuală a punctelor multiple de vedere ale tuturor părților interesate, cu rezultate durabile pe termen lung. Studiul adună o scurtă selecție de proiecte contemporane care exemplifică cele mai recente tendințe în crearea unor facilități culturale remarcabile în întreaga lume.

Putem vedea că astfel de zone pot avea o viață diferită, păstrând vechea identitate, dar refuncționalizate. Ultimele tendințe din practica și experiența internațională, tratează de la concept până la inserarea obiectului arhitectural într-un context restrâns din spațiul urban sau în relație cu mediul construit și natural. Proiectele prezintă modele de alocare a spațiului, în acord cu influentele din teren și susțin eforturile pentru planificarea clădirilor rezonabile din punct de vedere al prețulu și aspectului, flexibile și functionale pe toată durata zilei și nopții; a fost propusă introducerea modulelo functionale și o schemă funcțională simplă care să ghideze configurarea ansamblurilor. Arhitecții trebuie să îndeplinească noile cerințe, trebuie să aibă cunoștințe tehnice și organizaționale superioare; toate clădirile trebuie să îndeplinească mai multe obiective tehnice, tehnologice și estetice corespunzătoare noilor criterii: pe lângă economia tradițională, rezistența și durabilitatea, sunt necesare eficiența, competitivitatea și performanța energetică.

\subsection{Clădirea „dăruiește" jumătate din amplasamen} ca spațiu public pentru artistti de artă stradală.

Centrul Național de Artă și Cultură „Georges Pompidou" (NACC), cunoscut în mod obișnuit ca "Centre Pompidou" și colocvial „Beaubourg" este situat în districtul 4 al Parisului. Clădirea conține galerii de expoziții temporare majore, săli de concerte și teatre, prima lectură publică a biblioteci din Europa [5]. Pe ambele părți ale pieței, două clădiri primesc Institutul de Cercetare și Coordonare Acustică-Muzică (IRCAM) și atelierul Brâncuși. 
Proiectul realizat de arhitecții Renzo Piano și Richard Rogers a fost singurul dintre toate proiectele propuse, care implementează volumul clădirii pe o orientare nord-sud, respectând cartierul urban (cu axele Boulevard Sebastopol și străzile Saint-Martin și Fox). Propunerea lor a permis, de asemenea, să ocupe doar jumătate din teren, eliberând o esplanadă largă: piața, facilitând recepția publicului și o legătură mai fluidă între clădire și oraș. Aceste spații publice polivalente au devenit emblematice pentru oraș. Interpreții-actori de stradă însuflețesc piața orientată spre NACC. Potrivit datelor furnizate de ONT-Turism în Franța, acest loc a fost cel mai vizitat site turistic în anul 2006.

3.2 Clădirea „oferă” publicului întregul amplasament și acoperișurile, pentru promenadă, belvedere în conexiune cu apa.

Pentru Opera și Baletul Den Norske - Oslo (Norvegia) proiectat de arhitectii Snøhetta în 2008, site-ul ales a fost o zonă portuară din centrul orașului Oslo. Opera din Oslo este casa operei The Norwegian National Opera and Ballet și a teatrului de operă național din Norvegia. Clădirea este situată în cartierul Bjorvika din centrul Oslo, în fruntea Oslofjord. Structura conține un auditoriu principal cu 1.364 de locuri și alte două spații de performanță care pot găzdui 200 și 400 de locuri. Suprafețele exterioare înclinate ale clădirii sunt acoperite cu marmură italiană și granit alb și îl fac să stralicească precum apa [6]. A fost deschis în primăvara anului 2008 și proiectul a cucerit „Premiul european pentru spațiul public urban" - Barcelona 2010, datorită conceptului inovator de a acorda funcției publice importanța majoră [7]. Spațiul public avansează, creează buzunare, sapă texturi și generează relief. Manifestul menționat pentru soluții constă în protejarea pietonilor, oferind spațiu către piața publică; crearea de legături cu spațiile interioare, crearea de poduri, conexiuni cu cartierele dorite ca trasee pietonale viabile. A devenit primul reper al Norvegiei, creând un reper în oraș, oferind veder panoramice deosebite și creând propriul peisaj urban conectat la apă.

\subsection{Activatori urbani - spații de integrare.}

Reconstrucția ulterioară a centrului orașului Rotterdam (Olanda) a eliberat un spațiu liber între fațada principală a catedralei și canalul Delftsevaart. Aceasta este cunoscută sub numele de Grotekerkplein, un pătrat cu latura de aproximativ saptezeci de metri [8]. Cu toate acestea, mediocritatea clădirilor din jurul ei și slaba activitate comercială la nivelul străzii i-au conferit aspectul neplăcut ale unei curți goale. În afara unei statui în onoarea lui Erasmus și a câtorva copaci aliniați în rânduri duble, suprafața pătratului era lipsită de conținut și avea o absență clară de dinamism. În 2004, cu scopul de a organiza programatic acest spațiu și de a consolida definiția limitelor sale fizice, o organizație non guvernamentală privată a sugerat primăriei că un mic pavilion-teatru ar putea fi insera pe singura parte neconstruită a pătratului. Podiumu de teatru - Rotterdam (Olanda), proiectat de Atelier Kempe în 2009, de asemenea, câștigă „Premiul european pentru spațiul public urban" - Barcelona 2010 [9]. Pe lângă dotarea pieței cu un nou accent pentru evenimente, pavilionul se ridică ca un corp ambivalent. Datorită transparentei structurii sale și flexibilității închiderii verticale cu ajutorul perdelei glisante, poate acționa ca o limită opacă pentru a consolida limita Grotekerkpleinului sau poate deven un element semnificativ de legătură a piațetei cu canalul Delftsevaart. Orașul influențează activitățile ce se desfășurau în trecut într-o zonă majorita pietonală, cursul de apă adiacent închizând acest loc de întâlnire, măsurat la scară umană, lăsând loc contemplării, dar și organizării unor evenimente 


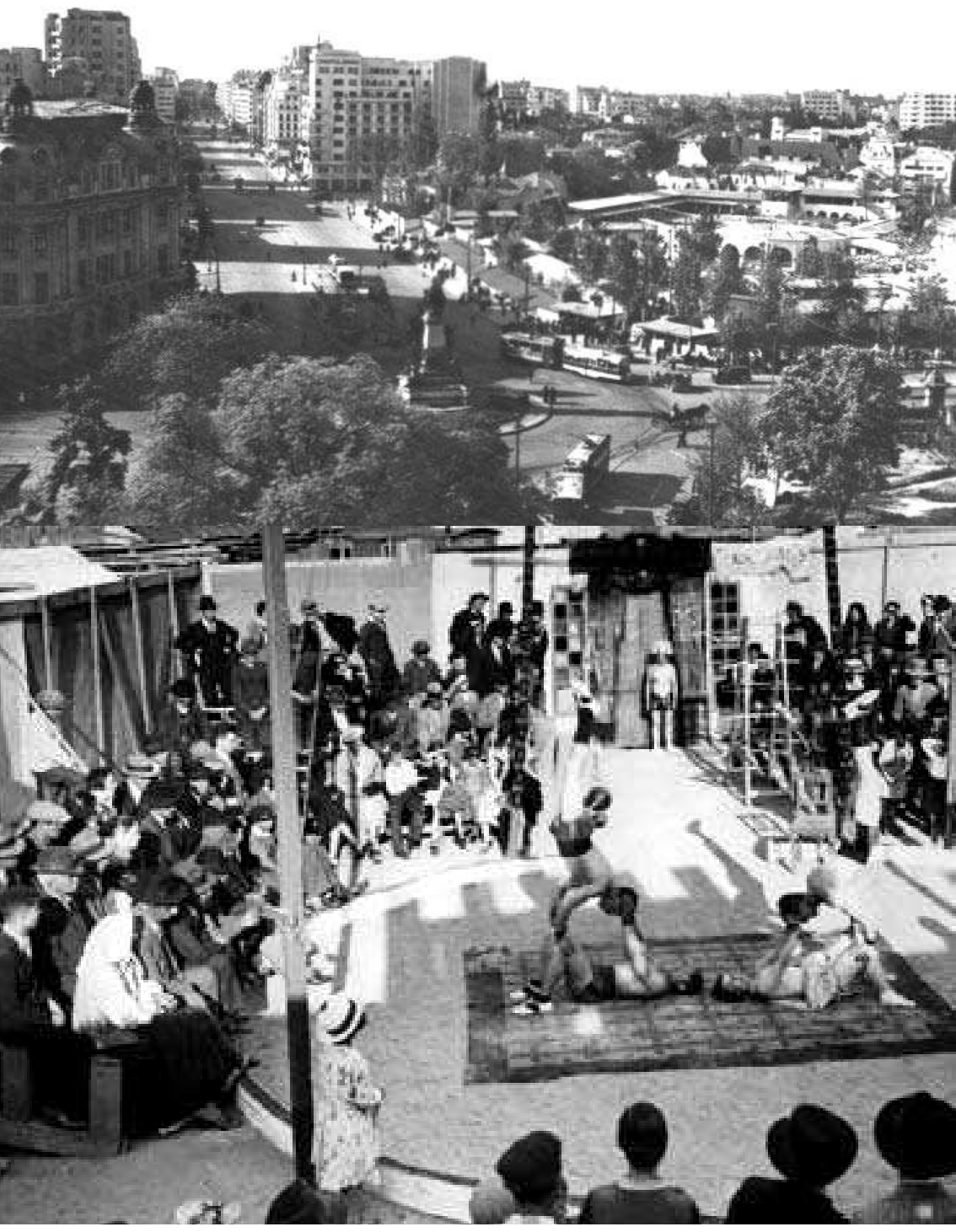

Fig.1-2* - Circul Krateyl - pe locul contemporanului T.N.B. vedere aeriană, și performanță artistică. Fig.1-2 - Krateyl Circus - on the place of the contemporary T.N.B. - aerial view and performance. *Imagini de la autor/ Images from the author comunitare. Conceptul indus PERCEPTTIA TIMPULUI atunci când se deplasează din centru, promenada simte nevoia de joncțiuni, forfecarea creând astfel un tesut, în raport cu centrul istoric. Exemplele prezentate arată că, în practica internațională, cele mai inventive solutii ale teatrelor moderne conectate la spațiile publice s-au găsit în locații total nonconformiste, așadar, trebuie să subliniem la această tendință un exemplu important al Bucureștiului contemporan. O plimbare în zona noastră de studiu poate rezerva suficiente surprize în ceea ce privește spațiul urban.

\section{Studiu de caz}

Regândirea arhitecturii prin redefinire este ilustrată de un proiect recent dezvoltat în Bucuresti, un oras care nu încetează să ofere situații provocatoare. Zona studiată este situată în imediata apropiere de "0" km, aproape de centrul istoric al orașului și Universitatea din București, un perimetru traversat de trasee de circulație auto, pietonale și de transport în comun. Stația de metrou „Universitate” este una dintre cele mai importante din linia de metrou București și dezvoltă un spațiu public larg subteran.

Piața „Nicolae Bălcescu” a fost în istoria orașului o zonă importantă pentru comerț (târguri) și divertisment, amintind de vechiul „Emil Krateyl Circus" (fig. 1 și 2), în același loc în care se află Teatrul Național București (TNB ) astăzi [10].

Povestea T.N.B. a fost adusă în mod regulat în centrul atenției de mai bine de jumătate de secol. Acoperirea marii săli a Teatrului Național, cu arcadele din tencuială dispuse pe mai multe registre, a fost răspunsul incidental la ordinea politică dată la începutul anilor '80, care avea ca scop schimbarea fațadelor rezultate din implementarea proiectului din 1965 redactat de arhitect Horia Maicu în colaborare cu arhitecți: Romeo Belea, Nicolae Cucu, Richard Bordenache jr. și alții (fig. 3). Problema proiectării Teatrului Național a format obiectul ma multor concursuri publice în 1956-57 și în 1962. [11] Imaginea propusă este un volum masiv care susține o streașină spectaculoasă care amintește de Mănăstirea Voroneț, precum și de Biserica Ronchamp de arh. Le Corbusier. Lucrările pentru noua structură de acoperire a fațadelor, finalizate în 1984 conform proiectului arh. Cezar Lăzărescu (fig. 4), au afectat confortul interior al sălii prin cresterea numărului de scaune având implicații riscante asupra structurii portante.

Conform proiectului recent de renovare și consolidare pregătit de arhitectul Romeo Belea, Ministerul Culturii a decis să restaureze imaginea teatrului din anii 1970, de asemenea în paralel cu regândirea întregii arhitecturi interioare [12] Teatrul, este in prezent restructurat în parametri optimi de vizibilitate, audibilitate, inteligibilitate ș ambianță pentru Sala Mare a teatrului. Clădirea Teatrului Național se dorește a fi un spațiu deschis publicului $10-12$ ore pe $\mathrm{zi}, \mathrm{cu}$ mai multe functii conexe, îndeplinind astfel criteriile programulu arhitectural de teatru: spectacole în mai multe săli (peste 3.000 de locuri față de 1720 inițial) și conexiuni cu alte activități culturale (galerii de artă expoziții, antichități, muzeu, muzică și spațiu recital de poezie, sală polivalentă, bibliotecă, baruri, cafenea, restaurant, etc.) (fig. 5). Re-functionalizarea spațiul public a vizat în principal în conceptul de deschidere largă pentru public. Planul de revitalizare integrează necesitățile infrastructurii, consolidează elementele istorice, asigură facilități turistice bune, creează spații de cartier și plimbări de patrimoniu decongestionează traficul și îmbunătățește calitatea spațiului pentru a permite atât cetățenilor, cât și turiștilor să se bucure de experiență. 
Caracterul public al Pieței este garantat de retragerea volumului principal (Hotelul Intercontinental) la marginea sitului, contribuiind astfel la crearea unui spațiu liber; astfel că piața publică devine parte a complexului de clădiri. Plasarea unui accent vertical pentru o dezvoltare semnificativă, aproape de limitele spațiale incerte, la sfârșitul unui profil longitudinal și a unei coborâri sinuoase, pare excesivă și disonantă. Rezolvarea unui volum masiv final (Teatrul Național), a plasat o limitare statică și nu o percepție dinamică; este un punct de finalitate exprimat, ce conduce la un capăt de perspectivă(fig. 6). O altă percepție a timpului este masa volumetrică prin poziția sa excentrică în raport cu centrul de greutate al site-ului, dă toate conotațiile pozitive ale spatiului public deschis. Libertatea oferită către organizarea de piețe-târguri, pasarele pietonale, zone comerciale, parcuri, monumente, implică ideea că spațiul poate deveni „scenă” neconvențională multiplă, mai ales că putem prevedea inserții temporare, neinvazive, bazate pe structuri ușoare etc. $O$ inițiativă mai veche s-a materializat: în fata teatrului, a fost ridicat un monument dedicat lui Ion Luca Caragiale „Trăsura arlechinului" sculptată de Ioan Bolborea (fig.7). Probabil se va organiza un concurs pentru identificarea unei soluții pentru amenajarea acestei părți a Pieței Universității, care trebuie să facă referire la soluția renovării teatrului.
Fig.3* - revenirea (în 2007) la proiectul din 1965 întocmit de arhitectul Horia Maicu în colaborare cu arhitecți: Romeo Belea, Nicolae Cucu, Richard Bordenache jr. si altii

Fig. 3* - the return (in 2007) to the 1965 project drafted by architect Horia Maicu in collaboration with architects: Romeo Belea, Nicolae Cucu, Richard Bordenache jr. and others Fig. 4 - TNB - spațiul public gol. Foto: M. Stănculescu Fig.4* -- TNB - the empty public space. Photo: M. Stănculescu Fig. 5* - imagine a spațiului public cu proiectul din 2007 elaborat de arhitecții: Romeo Belea și Antonio Teodorov Fig. $5^{*}$ - image with public space with the 2007 project drafted by architects: Romeo Belea and Antonio Teodorov ${ }^{*}$ Imagini de la autor/Images from the author
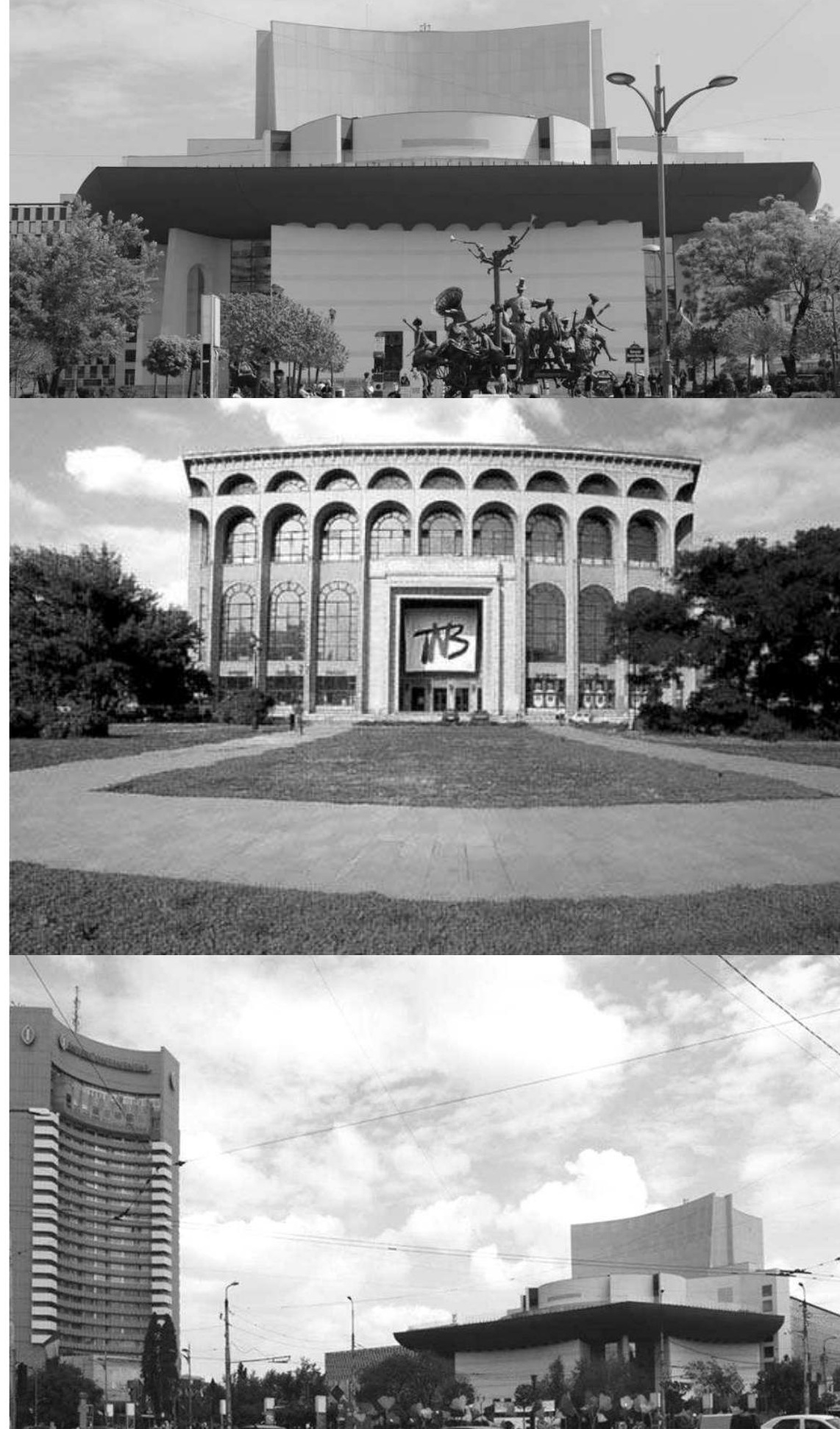

și dimensiuni diferite. Spațiul este fizic, incluzând arhitectura și forma urbană. Spațiul este, de asemenea, construit social prin diferite forme de intervenții umane. Spațiul este contestat și devine un motiv pentru conflicte serioase. Spațiul este prezentat și spațiul reprezintă. Pentru planificare, managementul utilizărilor concurente pentru spațiu, necesită interventii complexe. Crearea de locuri mai bune care sunt apreciate și care au identitate este o ambiție de planificare durabilă. Și, revenind la începutul acestei scurte reflecții, provocarea majoră a planificării spațiale este de a găsi soluții pentru un mileniu urban mai durabil. În timp ce globalizarea tinde să promoveze omogenitatea, orașele competitive au o identitate culturală individuală și particulară puternică. Astfel, în mod paradoxal, globalizarea solicită consolidarea identității locale și regionale. Nu este o sarcină ușoară căreia planificatorii urbani să trebuiască să îi facă față în context european. Promovarea culturii, a patrimoniului și a spațiilor creative din orașe, evitând în același timp implicații sociale negative, necesită multă sensibilitate și gândire strategică, în special în momentele în care orașele trebuie să facă față repercusiunilor financiare ale crizei globale.

Într-o perspectivă pe termen lung bazată pe parteneriatul privat / public, acest proiect ar fi ocazia de a reconsidera rolul și funcția unui sistem urban masiv format din zone publice și clădiri cu destinație publică. Prin urmare, trebuie făcut un inventar pentru a realiza un repertoriu al tuturor clădirilor culturale din zona centrală urbană. Descoperind diferite scenarii de regenerare urbană în funcție de conectarea lor, precum și personaje specifice fiecărei clădiri, putem experimenta o metodologie inovatoare de management teritorial pentru strategiile de coeziune a locurilor publice.
Știind că economia culturală se bazează atât pe produse culturale în circulație care folosesc structuri globale (atât materiale, cât și imateriale) și fixe (permanente: monumente, muzee ... și temporare: evenimente, târguri ...), ar fi posibilă proiectarea acestor noi clădiri de teatru și zonele lor publice ca fiind culturale într-un grad mai complex? Acestea trebuie să fie atractive (nu numai pentru studenți și cercetători) atât pentru simpli vizitatori cât și pentru turiști. Centrul orașului oferă adesea unele dintre elementele vitale ale stilurilor de viață „alternative”, precum identități puternice, oportunități de interactiune, diversitate și flexibilitate. Aceste fapte ilustrează necesitatea unei mai bune înțelegeri a relațiilor dintre efectele locului și capacitatea din centrul orașului de a atrage oameni și activităț creative. Planificarea vieții de noapte în oraș va fi în modalitățile prin care spațiul - constructia sa socială contestarea și managementul - sunt implicate în dinamica unei societăți diverse, adesea inegale; în consecință, spațiul este contestat și un motiv pentru conflicte serioase. Acest lucru poate fi explorat la diferite scări spațiale.

În conformitate cu Hanna Arendt - "Condiția umană” [13], spațiul public al democrației poate fi definit ca obiectul în care toate problemele discursive își pot arăta multitudinea și oamenii își pot arăta în mod liber propria lor pluralitate acționând și rostind opini plural. Astfel, spațiul public al democrației coincide cu spațiul politic al libertății. Pe această cale, am dor să subliniem noțiunea de spațiu ca: locul construit social și chiar contestat al întâlnirii noastre cu celălalt (i), arena fizică și metaforică în care conform Hannah Arendt - democratia poate nutri și înflori în sfera în care să solicite și să fi recunoscut drepturi depline de cetățenie. Dacă sensul (atunci când nu este scopul) politicii este libertatea pluralității și, prin urmare, a înțelege o situație 
politică înseamnă a recunoaște un cadru larg de puncte de vedere și poziții diferite din care situația poate fi considerată și judecată, această recunoaștere nu are indivizi ca obiect al său exclusiv, dar și spațiile și locurile orașului, negociază, în arealul orașului, diferite forme de interacțiune și conviețuire. Acesta nu este un proces ușor, natural sau automat. De fapt, percepția emoțională și plină de identitate a spațiului se schimbă și ea: frica și insecuritatea devin - în multe cazuri - semnele cele mai evidente, atât la nivel individual, cât și la nivel politic. (Fig. 8).

Cum se poate ca planificatorii să facă față cu toate aceste probleme? Ce experiență practică trebuie luată în considerare pentru a asigura pluralitatea și libertatea în spațiul orașului, care este și locul fizic al spațiului democrației? Care strategii impun progresul social, cum ar fi utilizarea mai corectă și / sau distribuirea spațiilor care îmbunătățesc calitatea vieții: spații în care tinerii se simt confortabil, spații pentru amestec cosmopolit, spații pentru democrație, spații pentru turiștii care vizitează Bucureștiul, spații verzi ș.a.

Scopul este de a discuta despre un nou fenomen spațial, modelat de activități temporare și utilizatori, care se manifestă ca o rețea de spații în continuă schimbare, formând astfel un oraș paralel și intermitent. Încorporarea spațiilor urbane în acest oraș intermitent, de către persoane sau grupuri, pune din nou în discuție caracterul incluziv al orașului și transformă spațiul urban într-o arenă, în care cetățenii încearcă să cucerească orașul din organizații(le) instituționale. Planificatorii urbani și factorii de decizie trebuie să se ocupe de diversitatea din ce în ce mai mare a cererilor și a dorințelor societății multiculturale.
6 Concluzii. re-construirea spațiilor publice (plurale) În ultimii ani, apariția unei noi culturi a mediulu inconjurător prezintă noi provocări pentru gestionarea spațiului public. Cultura eco-mediu este provocatoare pentru utilizarea terenurilor și pentru gestionarea spațiului public. Ideea generală a planului a fost să lucreze nu la un inventar al activelor listate, o abordare tradițională a culturi conservării, ci la corelațiile - funcționale, perceptive, simbolice - între active, având în vedere procesele ș dinamica schimbării, mai mult decât clădirile și monumente. Mișcările sociale urbane reclamă spații publice care reflectă preocupări mai puternice pentru sustenabilitate, schimbări climatice ș calitatea mediului. Care sunt așteptările, temerile ș nevoile locuitorilor din aceste zone? În funcție de ce valori, reguli și norme se formează spațiul urban contemporan? Pentru a facilita alegerile viitoare pentru locație și dezvoltarea spațiului teatral, această cercetare structurează un cadru teoretic care stabilește relații reciproce între procesele de proiectare și planificare și juxtapunerile ritmurilor cotidiene, discursului urban și practicilor asociate mediilor. Descoperirile teoretice care identifică modalități durabile legate de modelele de viață socială pot servi la formularea de ghiduri de proiectare pentru proiecte viitoare. Explorează o căutare de noi forme de medii urbane orientate spre viitor, care incubă și favorizează creativitatea ș inovarea, ca nevoi de bază atât în spațiile actuale, cât și în cele viitoare. Explorează problema „zonelor de prag" în dubla sa interpretare: ca locuri fizice în care grupurile marginale sau excluse sunt obligate să experimenteze acțiuni colective pentru a câștiga condiții de viață (urbane) mai bune sau ca metaforă a unui spațiu în sfera privat și public, care este, de asemenea, o precondiție a existenței spațiului public al democrației. 
În sfârșit, din punct de vedere economic, forma urbană fizică joacă un rol în accelerarea sau stoparea inovării. Deși există un acord larg potrivit căruia inovația este cheia succesului economic al orașelor, regiunilor și țărilor, în mod surprinzător se știe puțin despre legăturile precise dintre inovație și forma urbană fizică. Deși designul este o manifestare esențială a practicilor inovatoare, cum poate proiectarea urbană să favorizeze inovarea în orașe? Cum poate fi promovată inovația fără a submina identitatea, caracterul și moștenirea culturală a locurilor?

În căutarea construirii unei înțelegeri a calității spațiale, consider esențială natura relațională a spațiului care este concepută în funcție de dimensiunile temporale. Exemplul arată că o cheie în adaptarea la ritmul schimbării în cadrul producției spațiale contemporane este capacitatea practicienilor de a dezvolta obiceiul acțiunii reflective. Revitalizarea unei zone urbane prin construirea sau redefinirea unei clădiri de teatru necesare sau oportune - a fost surprinsă în câteva exemple internationale recente; integrarea unor clădiri de teatru sau a altor structuri pentru adăpostirea funcțiilor culturale, are ca rezultat revitalizarea și evoluția acelor zone ca spații civice cu atracții publice veritabile și multiple. Prin arta teatrului, atât situl, cât și reciproc clădirea teatrală oferă noi semnificații. Trebuie să privim designerii ca exploratori spațiali care abordează analizele spațiale din punct de vedere fenomenologic. Ei își asumă diferite roluri alternative, prin efectuarea de analize senzoriale, conceptuale, instituționale și ritmice ale locurilor. Definesc dialectica designului ca o întelegere dinamică a biografiei unui loc în următoarele momente: a) o direcție care conturează imaginea exterioară, b) un concept care generează o imagine profesională și c) viața care creează experiențe trăite și prezența civică pe termen lung a unui loc. În evoluția sa remarcabilă, domeniul acesta al creației devine din ce în ce mai eclectic și interdisciplinar, îmbogățit de influențele umaniste și de stiintele sociale și naturale.

Fig. $8^{*}$ - spațiul public al democrației amestecat cu reconstrucția clădirilor. Fig. $8^{*}$ - the public space of democracy mixed with building
reconstruction. *Imagini de la autor/ Images from the author

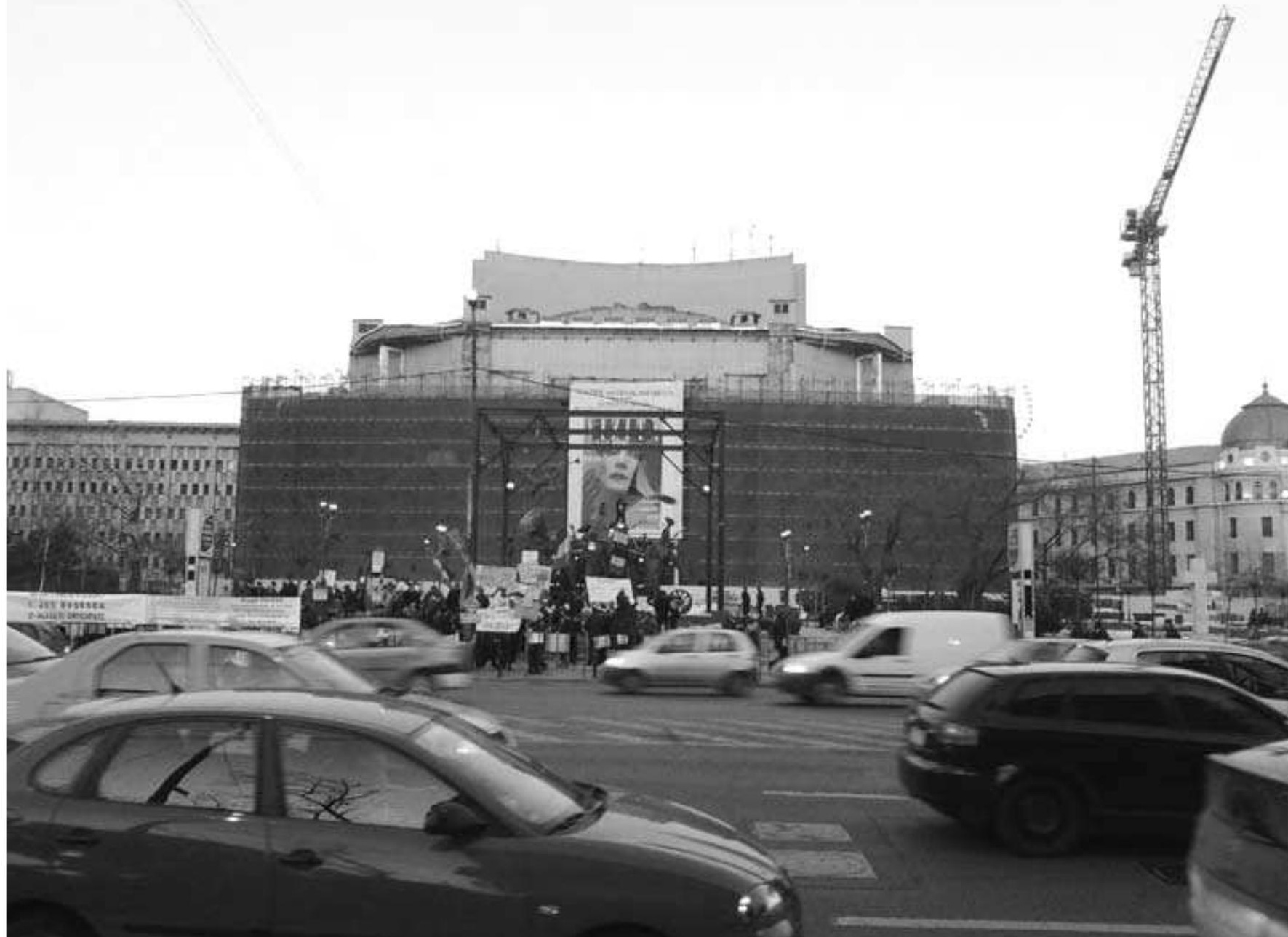


(english version)

1 Introduction - the significance of the subject

Challenged by an increasingly complex urban context, the theatre buildings must integrate their design into the existing urban fabric through a skillful and sensitive interpretation of the buildings purpose and relationship with the public. Rather than merely fulfilling an aesthetic purpose, today's design projects have cultural, political and social importance, and only those that succeed in reflecting these values, in combination with a novel approach to the practice of architecture, can be considered as spectacular. Bearing in mind these issues and criteria, the present study provides some of the newest practical requirements, for any possible further investments in theatre architecture, whether private, public or mixed and offers an illustration of the process of materializing the idea, the concept of the connection between the architectural building and the public space. This paper intended to be a support of documentation for anyone whishing to access those innovative ideas (also for students architects), in the time when thinking and designing of a theatre building is constantly changing (rethinking architecture by redefinition). The main idea followed is: the necessity of continuous redefinition of designing theatre spaces and buildings, is the only way to achieve the proliferation of this type of architecture. This requires solid knowledge of the past, even the immediate one, from wich we learn and constantly get inspired, to be prepaired for the future. Everything is viewed in a new, reorganized perspective, always returning the terms such as: development processes, variability, freedom of expression, simplicity and essentiality of space and equipment, reducing investment and operating costs, ability to adapt over time, intensive use of space. Currently the types of activities performed in these buildings can be modified, are in constant change, programs are aggregated and become more complex, or, conversely, tend to a "poverty" and simplification, so the architect is being permanently faced with new circumstances. The knowledge's he gradually acquired asked time for experimentation and improvement. A single person no longer possess all these data, which correlated with details to the urban criteria, and management criteria, conclude with a new approach: multidisciplinary teams of specialists. On the other hand, the development of a contemporary city generates areas unused, forgotten, fractured zones that become true barriers in the territory, functional voids, even if there are located close to the central area. Today the field of public urban space, still contain unused spaces suitable for re-function purpose. The study contains an entire complex of questions, doubts and contradictions, which are specific for an organism as complex and permanently vivid such is the urban space. I try to underline the ideea of conquer new places to relax and interconnect to the city, by development of urban public spaces in the adjacent of cultural buildings [1].

\section{Methodology}

As a consequence of the general evolution we assist today a change in philosophical attitude, and accepting the ideas of continues changes, the study of border areas, relative truths, a new attitude about values (acceptance of the values coming from different cultures, re-discuss the human needs) and returning of the attention to the person, the beneficiary or user of the architecture. Architecture tends to solve the problems of communities, of groups, accept the cultural differences, and marks the importance of human emotions and perceptions. How can we do this? According to Bruno Zevi: "life always has decomposed, has articulated, has added 
and than has remodeled" [2]. So, based on this affirmation, I was inspired to use the methodology of inventory as a previous condition: "Inventory means to clarify the semantic. We did not use words before analysing their profound content" [3].This decomposition method in separate activities, criteria or ideas is followed by inventory method and then recompose following the reintegration principle. To make a model which mime the reality, also should take into account to include the time aspect. Louis Kahn indicates to us the necessity to establish the difference between spaces for route and spaces for stay: "the space must be lived, socially used, capable to receive and emphasize the value of events" [4]. The main methods include documental research, statistical data and semi-structured interviews with creative activities' workers and managers, and members of local authorities' technical staff. By applying qualitative research methods and architectural interpretive observation, as part of urban renewal processes, may it become a means to build a continuous and direct relationship between territory, stakeholders, institutions and citizens. also use the rhythm-analyses research method, through which I compare and contrast the associated social life into public spaces related to theatre buildings.

\section{Research for example}

There are already large number of spectacular achievements in theatre buildings, which surprise by boldness, performance and how they respond the functional requirements and aesthetic. The following projects are analyzed and presented to you for the reason of their assiduous effervescence to search the conceptual and formal identity conected to the public space. Overflowing with positive energy, the projects reflected a youthful vision of thinking, a new way of filling space above and underground, the social involvement of citizens, and the conceptual approach of multiple points of view of all stakeholders, with long-term sustainable results. The study gathers a selection of few contemporary projects from the last few years that exemplify the latest trends in the creation of prominent cultural facilities around the world. We can see that such areas may have a different life, keeping the old identity, but re-functionalized. The latest trends from the international practice and experience, from the concept to the insertion of the architectural object in closer neighborhood, in urban space and in relationship with the built and the natura environement. Projects present space allocation models, in agreement with the field stakeholders, sustain their efforts for planning buildings reasonable in terms of price and appearance, flexible and functional throughout the period of day and night; the introduction of functional modules is been proposed and a simple functional scheme guide the assembles. Architects must fulfill new requirements, must have superior technical and organizational knowledge; all buildings must comply several technical goals, technological and aesthetic corresponding of new criteria: in addition to the traditional economy, strength and durability, is required efficiency, competitiveness and energy performance.

\subsection{The building "shares" half the site as public} space for street arts performers.

The National Centre for Art and Culture "Georges Pompidou" (NACC), commonly known as "Centre Pompidou" and colloquially "Beaubourg" is located in the 4th arrondissement of Paris. The building contains major temporary exhibition galleries, concert halls and theaters, the first public library reading in Europe [5]. On both sides of the piazza, two outbuildings welcome the Institute for Research 
and Coordination Acoustic-Music (IRCAM) and the workshop Brâncuşi. The project made by architects Renzo Piano and Richard Rogers was the only one of all proposed projects, which implement the building along a north-south orientation, respecting the urban district (with the axes of the Boulevard Sebastopol and rue Saint-Martin and the Fox). Their proposal also allowed to occupy only half the ground by releasing a wide esplanade, the piazza, allowing the public reception and a more fluid connection between the building and the city. These multipurpose public space has become emblematical for the city. Street performers enliven the plaza facing the NACC. According to ONT- Tourism in France, this place was the most visited sites in 2006.

3.2 The building "offer" the entire site and the roofs to the citizens, for walking, watching and get connected to the water.

For Den Norske Opera \& Ballet - Oslo (Norway) designed by architects Snøhetta in 2008, the site that was chosen was an harbour area of downtown Oslo. The Oslo Opera House is the home of The Norwegian National Opera and Ballet, and the national opera theatre in Norway. The building is situated in the Bjorvika neighbourhood of central Oslo, at the head of the Oslofjord. The structure contains the main auditorium seats 1,364 seats and two other performance spaces that can seat 200 and 400 . The angled exterior surfaces of the building are covered with Italian marble and white granite and make it appear to rise from the water [6]. It was opened in the spring of 2008 and the project conquer "The European prize for urban public space" - Barcelona 2010, thanks to the innovative concept of giving to the public function the major importance [7]. The public space advance, creates pockets, dig textures and generates relief. The manifest stated for solutions is to protect pedestrians by providing space to the public plaza; making connection with the inner-spaces, creating bridges, connections to neighborhoods, desired as viable pedestrian routes. It became Norway's first landmark, creating a pole into the city, offering great panoramic views and creating it's own urban landscape connected to the water.

\subsection{Urban activators - spaces of integration.}

The subsequent reconstruction of the city centre of Rotterdam (Netherlands) freed a vacant space between the main facade of the cathedral and the Delftsevaart canal. This is known as the Grotekerkplein, a square of some seventy by seventy metres [8]. However the mediocrity of the buildings around it and the scant commercial activity at street level gave it the lacklustre appearance of an empty backyard. Apart from a statue in honour of Erasmus and a few trees lined up in double rows, the square's surface was tediously devoid of content and it suffered from a clear absence of dynamism. In 2004, with the aim of programmatically organising this space and reinforcing the definition of its physical limits, a non-profit-making private organisation suggested to the Council that a small paviliontheatre could be inserted on the only non-built-up side of the square. Theatre Podium - Rotterdam (Netherlands) designing by Atelier Kempe Thil in 2009 also conquer "The European prize for urban public space" - Barcelona 2010 [9]. Besides equipping the square with a new focus for events, the pavilion rises as an ambivalent body. Thanks to the transparency of its structure and the mutability of its vertical closing by means of the sliding curtain, it can act as an opaque limit to reinforce the limit of the Grotekerkplein or become a threshold significantly connecting the square with the Delftsevaart canal. The city influences the activities taking place in the past as a mostly pedestrian area, 
the adjacent water course was easy to close, direct contact, measured in human step, which leaves room for contemplation and organizing a community event. The induced concept TIME PERCEPTION when they move from the center, the promenade feels the needed of junctions, hence shearing thus creating a tissue, in relation to historical center.

The examples presented show that in international practice, the most inventive solutions of modern theaters connected to public spaces were found in totally non-conformist locations, so, subscribe to this tendency with an important example of contemporary Bucharest. A walk in our study area may reserve enough surprises in regards the urban space.

\section{Case study}

Rethinking architecture by redefinition is about one recent very big project developped in Bucharest, one city which never stops offering provocative situations. The studied area is located in proximity to " 0 " km, close to historical City Center, and The University of Bucharest, arount the perimeter featuring a set of circulation routes of for drivers and pedestrians, and common transportation. "University" Subway Station is one of the most important of the Bucharest metro line and develop an large subterranean public space.

"Nicolae Balcescu" Square was in history of the town an important area for commerce (fairs) and entertainment, remembering the old "Emil Krateyl's Circus" (fig. 1 and 2), in the same place where is located Bucharest National Theatre (T.N.B.) today [10]. The story of the T.N.B. has been regularly brought into focus for more than half a century. The covering of the grand hall of the National Theatre with its plaster archways arranged on several registers, was the incidental response to the political order given in the early 1980s, which aimed to changed the facades resulting from the implementation of the 1965 project drafted by architect Horia Maicu in collaboration with architects: Romeo Belea, Nicolae Cucu, Richard Bordenache jr. and others (fig. 3). The issue of the renovation of National Theatre has formed the object of several public contests in 1956-57 and in 1962. [11]

The image proposed is a massive volume which supported a spectacular canopy remembering Voronet Monastery, and also Ronchamp Church by arch. Le Corbusier. The works for new covering structure, finished in 1984 according to the project of arch. Cezar Lăzărescu (fig. 4), affected the interior comfort of the hall by increasing the number of seats with risky changes in the load bearing structure. According to the present renovation and consolidation project prepared by architect Romeo Belea, the Ministry of Culture has decided to restore the 1970's image of theatre, also in parallel with rethinking the entire interior architecture [12].

It will be restructured the optimal parameters of visibility, audibility, intelligibility and ambience Great Hall of the theater. National Theatre building will become a public open 10-12 hours daily, with more functions, running the criteria of major buildings in the world theater: performances in several halls (over 3,000 spots from 1720 to present) and show relationships various spectators (art galleries, exhibitions, antiques, museum, music and poetry recital space, multi purpose hall, library, bars, cafe, restaurant, etc) (fig. 5). Re-function the public space aimed mainly-entered in the concept of wide opening to the public.

The revitalization plan integrates the infrastructure needs, strengthen the historical elements, providing good tourist facilities, creates neighborhood spaces 
and heritage walks, decongest the traffic and improve the quality of space to allow both the people of the city and tourist to enjoy the experience. The public character of the Plaza is guaranteed by the withdrawal of principal volume (The Intercontinental Hotel) to the edge contribute to create a public space; so the public square becomes part of the building complex. Placing a vertical focus for significant development close to the uncertain spatial boundaries, at the end of a longitudinal profile and a sinuous descent, seems excessive and dissonant. Solving by a prospective end massive volume (The National Theatre), placed a static limitation and not a dynamic perception; is a point of finality expressed, resting lead to vision after completing a varied route (fig. 6). Another time perception is the volumetric mass by its eccentric position relative to the center of gravity of the site, gives all the positive connotations of public open space. Freedom to markets, pedestrian walkways, shopping areas, parks, monuments, the space can become unconventional "scenes", especially since we can foresee temporary inserts, non-invasive, based on light structures, etc. An older initiative materialized: in front of theatre, an monument dedicated to Ion Luca Caragiale was erected "The Harlequin Carriage" sculpted by loan Bolborea (fig.7). The Bucharest City Hall probably will organize a contest to identify a solution for the arrangement of this part of the University Square, which could have also referred to the solution of the renovation of the theatre.

\section{Theatre building - public space - urban space}

Building works and operational optimization of the National Theatre "I.L.Caragiale" in Bucharest, define the new cultural objectives and contribute to a new strategy: to match the technical requirements, to provide safetyness and secure to the public which access the cultural act. What is new compared to other studies is precisely the designing of the modern theatre spaces according of multi criterial issues and not unilaterally. Regarded as a CITY FRAGMENT the building of the theatre "aspire" to become accessible for everyone; it remains faithful to a model of direct relationship, immediate, a chance of meeting between human beings, undivided by any space obstacle. The subway is seen as a tool of social interaction, seen as a public space, in the determination of certain behavior, but also bisensual relationship that itself consists of user needs.

Environmental issues: green design, energy consumption, maintenance costs are now covered from the design stage. Technology provides for architects and designers of various specialties freedoms, but also constraints; modern materials, modern design. The evolution of architectural expression must following "green" trends. Studying these proposals is underlining the trend of reconsidering the patterns, by proposing appropriate directions of development according to social, economic and technological realities. "The theater building, in the great cultural capitals shows open spaces where people can spend all day, whether or not they go to see the play," says Prof. Dr. Arch Romeo Belea, giving the example of Barbican Theatre in London.

The main idea pursued and demonstrated by this survey is the perpetual necessity to redefine the theater performances and theater spaces, as to achieve the proliferation of this kind of art in the future.Current tendency of permanent modeling theatrical shows for maintaining and increasing public interest, require thorough study of the past, the factors which have caused dramatic changes in both the interpretation and the configuration of the 
acting scenes, for outlining potential evolution options of theatrical buildings architecture. The evolution of indoor theatre spaces leads to a "provisional" approach even in the case of durable buildings; the spectacle spaces possibilities of transforming according to the director's indications is needed. The casing is the architect's privilege, addressing to the public with his vision and the spectacle inner box is left entirely up to the director in the process of realizing his perception of dramatic opera. The models proposed are rather a principle "frame" than a physical space materialized. For visualizing future theater areas, I consider more important the dimension related to flexibility over time which offers multiple configuration possibilities for theatrical events rather than its geometric configuration

Urban design is the key factor in shaping and managing space and generate the wished for quality urban spaces. The concept of space and concomitantly that of spatial quality includes different meanings and dimensions. Space is physical, including architecture and urban form. Space is also socially constructed through various forms of human interventions. Space is contested and a reason for serious conflicts. Space is presented and space represents. For planning, the management of the competing uses for space requires complex interventions. The making of better places that are valued and have identity is an enduring ambition of planning. And, returning to the start of this brief reflection, the major challenge of spatial planning is to find solutions for a more sustainable urban millennium.

While globalization tends to promote homogeneity, competitive cities have a strong individual and particular cultural identity. Thus globalization paradoxically calls for strengthening local and regional identity. It is not an easy task planners have to face in Europe. Promoting culture, heritage and creative spaces in cities, while avoiding negative social implications, requires much sensitivity and strategic thinking, particularly in times, when cities have to cope with the financial repercussions of the global financial crisis.

In a long-term perspective based on private/public partnership, this project would be the occasion to rethink role and function of a massive urban system made of public areas and buildings with public destination. Therefore, an inventory must be carried out in order to make a repertory of all cultural buildings in the urban central area. Figuring out different scenarios of urban regeneration according to connect them, as well as specific characters of each building, we can experiment an innovative methodology of territorial marketing for public places cohesion strategies.

Knowing that cultural economy are based both on circulating cultural products that use global structures (both material and immaterial items) and fixed ones (permanent: monuments, museums... and temporary: events, fairs...), would it be possible to design these new theatre buildings and public areas as a cultural in a full degree? They must be attractive (not only for students and researchers) for both simple visitors and tourists. City-centre often provide some of the vital elements of 'alternative' lifestyles, such as strong identities, opportunities for interaction, diversity and flexibility. These facts illustrate the need for a better understanding of the relationships between place effects and city-centre capability to attract creative people and activities. Planning Night Life in the City will be the ways that space - its social construction, contesting and 
management - are implicated in the dynamics of a diverse, often unequal, society; consequently, space is contested and a reason for serious conflicts. This can be explored at various spatial scales.

According to Hanna Arendt's "The Human Condition" [13], the public space of democracy can be defined as the ambit where all the discursive issues can show up their many-sidedness and people can freely show up their own plurality by acting and uttering their plural opinions. Thus, the public space of democracy coincides with the political space of freedom. In this track, we would like to emphasize the notion of space as: the socially constructed and even contested place of our meeting with the other(s), the physical and metaphorical arena where - according to Hannah Arendt - democracy can nurture and flourish and the sphere where to claim for and have recognized full rights of citizenship. If the sense (when not the aim) of politics is the freedom of plurality, and therefore understanding a political situation means acknowledging a large framework of different viewpoints and positions from which the situation can be considered and judged, this recognition does not have individuals as its exclusive object but also the spaces and places of the city, negotiating, in the city spaces, different forms of interaction and cohabitation. This is not an easy, natural or automatic process. As a matter of fact, the emotional and identity-laden perception of space changes as well: fear and insecurity are becoming in many cases - the most evident signs, at the individual as well as the political level. (Fig. 8).

How can planning and planners cope with all this? Which theoretical issues and practical experience have to be considered, in order to ensure plurality and freedom in the city space that is the physical place of the space of democracy? Which discuss strategies for social progress, such as fairer use and/or distribution of spaces that improve quality of life: spaces where young people feel comfortable, spaces for cosmopolitan mix, spaces for democracy, spaces for tourists visiting Bucharest, green spaces and so on

The aim is to discuss a new spatial phenomenon, shaped by temporary activities and users, that manifests itself as a continuously changing network of spaces, thus forming a parallel and intermittent city. The incorporation of urban spaces in this intermittent city, by individuals or groups, time and again questions the inclusive character of the city and converts the urban space into an arena, in which citizens are trying to conquer the city from institutional organizations. Urban planners and policymakers must deal with the increasing diversity in demands and whishes from the multicultural society.

\section{Conclusions. re-building public (plural) spaces}

In recent years, the emergence of a new environmental culture is posing new challenges to public space management. The emerging environmental culture is challenging land use and public space management. The general idea of the plan was to work not on an inventory of listed assets, a traditional approach of the culture of conservation but on the correlations - functional, perceptive, symbolic - between assets, considering processes and dynamics of change, more than buildings and monuments. Urban social movements are claiming public spaces that reflect stronger concerns for sustainability, climate change and environmenta quality. What are the expectations, fears and needs of the inhabitants of these areas? According to which values, rules and norms is contemporary urban space being shaped? To facilitate future choices for location and theatrical space 
development, this research structures a theoretical framework that lays out mutual relationships between design and planning processes, and the juxtapositions of everyday rhythms, urban discourse and practices associated with the environments. The theoretical findings that identify sustainable ways relating to models of social life may serve in formulating design guidelines for future projects. Explore a quest for new forms of future-oriented urban environments incubating and fostering creativity and innovation as the basic needs of both today's and future's spaces. Exploring the issue of the 'threshold areas' in its double interpretation: as physical places where marginal or excluded groups are forced to experiment collective actions in order to gain better (urban) life conditions or as metaphor of an infra-space between private and public sphere, which is also as a precondition for the existence of the public space of democracy.

Finally, from an economic point of view, the physical urban form plays a role in speeding - or retarding innovation. While there is broad agreement that innovation is the key to the economic success of cities, regions and countries, surprisingly little is known about the precise links between innovation and physical urban form. While design is a key manifestation of innovative practices, how can urban design foster innovation in cities? How can innovation be promoted without undermining the identity, character, and cultural heritage of places? In search for building an understanding of spatia quality I consider essential the relational nature of space that is conceived according to temporal dimensions. The example shows that a key in adapting to the pace of change within the contemporary spatial production is the practitioners' capability to develop the habit of reflective action. The revitalization of an urban area by erecting or redefinition of a theatre building - necessary or opportunistic - was captured in a few recent international examples; the integration of some theatre buildings or other structures to house cultural functions, has the result to revitalize and evolve those areas as civic spaces with genuine and multiple public attractions. Trough the art of theatre, both the site, as much as the theatrical building reciprocal provide new meanings. You must look at designers as spatial explorers that approach spatial analyses from a phenomenological viewpoint. They assume different roles alternatively, by performing sensorial, conceptual, institutional, and rhythmanalyses of places. I define the design dialectics as a dynamic understanding of a place's biography across the following moments: a) a sense that contours an external image, b) the conception that leads to a professional image, and c) the life that creates lived experiences and an enduring civic presence of a place. In its remarkable evolution, the field has become increasingly eclectic and interdisciplinary, enriched by influences from the humanities, and social and natural sciences. 


\section{Referințe/ References}

[1] Prezenta lucrare de poziție (profesională) servește, de asemenea, ca o orientare cu privire la oportunitatea unui concurs public de arhitectură care include spațiul urban situat în fața TNB și a Hotelului Intercontinental.

[1] The present position paper serves also as a guideline regarding the opportunity of a public architectural competition which includes the urban space located in front of TNB and The Intercontinental Hotel.

[2] Zevi, Bruno - Codul anti-clasic - limbajul arhitecturii moderne, tradus de G. Tabacu, Ed. Paideia București 2000, p. 32-33

[2] Zevi, Bruno - The anti classical code - the language of modern architecture, translate by G. Tabacu, Ed. Paideia Bucharest 2000 , pg 32-33

[3] Id. [2], pg 14

[4] Id. [2], pg 40-41

[5] Dufrene, Bernadette - Centre Pompidou 30 de ani de istorie, Editions du Centre Pompidou, Paris, 2007

[5] Dufrene, Bernadette - Centre Pompidou 30 years of History, Editions du Centre Pompidou, Paris, 2007

[6] Opera și balet Den Norske - Oslo (Norvegia). Arhitecți: Snohetta 2008, (Arhitectii și Bucureștiul 27.03.2010)

[6] Den Norske Opera \& Ballet - Oslo (Norway). Architects : Snohetta 2008, (Arhitectii si Bucureștiul 27.03.2010)

[7] Premiul european pentru spațiul public urban - Barcelona 2010 - www.cccb.org - Centre de Cultura Contemporània de Barcelona - Montalegre 5 - 08001 Barcelona

[7] European prize for urban public space - Barcelona 2010 www.cccb.org - Centre de Cultura Contemporània de Barcelona Montalegre 5 - 08001 Barcelona

[8] Podium de teatru - Rotterdam (Olanda). Atelier Kempe Thil. 2009 (Arhitectii și Bucurestiul 27.03.2010)

[8] Theatre Podium - Rotterdam (Netherlands). Atelier Kempe Thil. 2009 (Arhitectii si Bucurestiul 27.03.2010)

[9] Id [7] - Activatori urbani: Podium de teatru și Grotekerplein, Rotterdam [Olanda] Mențiune specială 2009

[9] Id [7] - Urban Activators: Theater Podium \& Grotekerplein, Rotterdam [Netherlands] 2009 Special Mention

[10] în 1954, Circul de Stat situat pe Bvd. Nicolae Bălcescu, în Circul fostului Emil Krateyl, în același loc în care se află T.N.B. în zilele noastre, (lacob, Ana - $\mathrm{O}$ istorie a circului românesc: de la pehlivani acrobati

www.historia.ro/exclusiv_web/general/articol/o-istorie-circuluiromânesc-pehlivani-acrobaţ̧i)

[10] in 1954, State Circus located on Bvd. Nicolae Bălcescu, into the former Emil Krateyl's Circus, in the same place where is located T.N.B. in our days, (lacob, Ana - O istorie a circulu românesc: lays, llacob, Ana -

acrobaţi www.historia.ro/exclusiv_web/general/articol/o-istorie-circuluiromânesc-pehlivani-acrobațil

[11] În 1956-1957, competititia pentru Piața „N. Bălcescu”, iar în 1964, concursul pentru Proiectul Teatrului Național. (Ioan Augustin - Concursuri de arhitectură în perioada comunistă www.arhiforum.ro/agora/

[11] In 1956-1957 the competition for "N. Bălcescu" Square, and in 1964 the competition for The National Theatre Project. (loan Augustin - Architectural contests in communist period) www.arhiforum.ro/agora/

[12] (proiectul de 51 de milioane de euro, suma de 27 de milioane de euro va proveni din credit extern) - Interviu cu Adriana Popescu, Departamentul de Strategie Culturală, Comunicare și PR pentru Ziarul Adevărul: 2011-04-28

[12] (51 million euro's project, the amount of 27 million euro's will come from external credit) - Interview with Adriana Popescu, Department of Cultural Strategy, Comunication and $P R$ for Newspaper Adevărul: 2011-04-28

[13] Arendt, Hannah (1958) Condiția umană (Chicago, IL: Universitatea din Chicago Press). Arendt, Hannah (2005) Promisiunea politicii (New York: Schocken Books).

[13] Arendt, Hannah (1958) The Human Condition (Chicago, IL: The University of Chicago Press). Arendt, Hannah (2005) The Promise of Politics (New York: Schocken Books).

\section{Citare articol curent / Citation}

(Ro)

Stănculescu M. (2021). Situl și clădirea teatrului, prin arta teatrului, oferă reciproc noi semnificații. în Teoria proiectului de arhitectură. Idei construite. SP FA UAUIM. EUIM - Editura Universitară Ion Mincu, București.

Stanculescu M. (2021). The site and the theatre building, through the art of theater, reciprocally provide new meanings. in Architectural design theory. Built ideas. SP FA UAUIM. EUIMIon Mincu University Publishing House, Bucharest. 


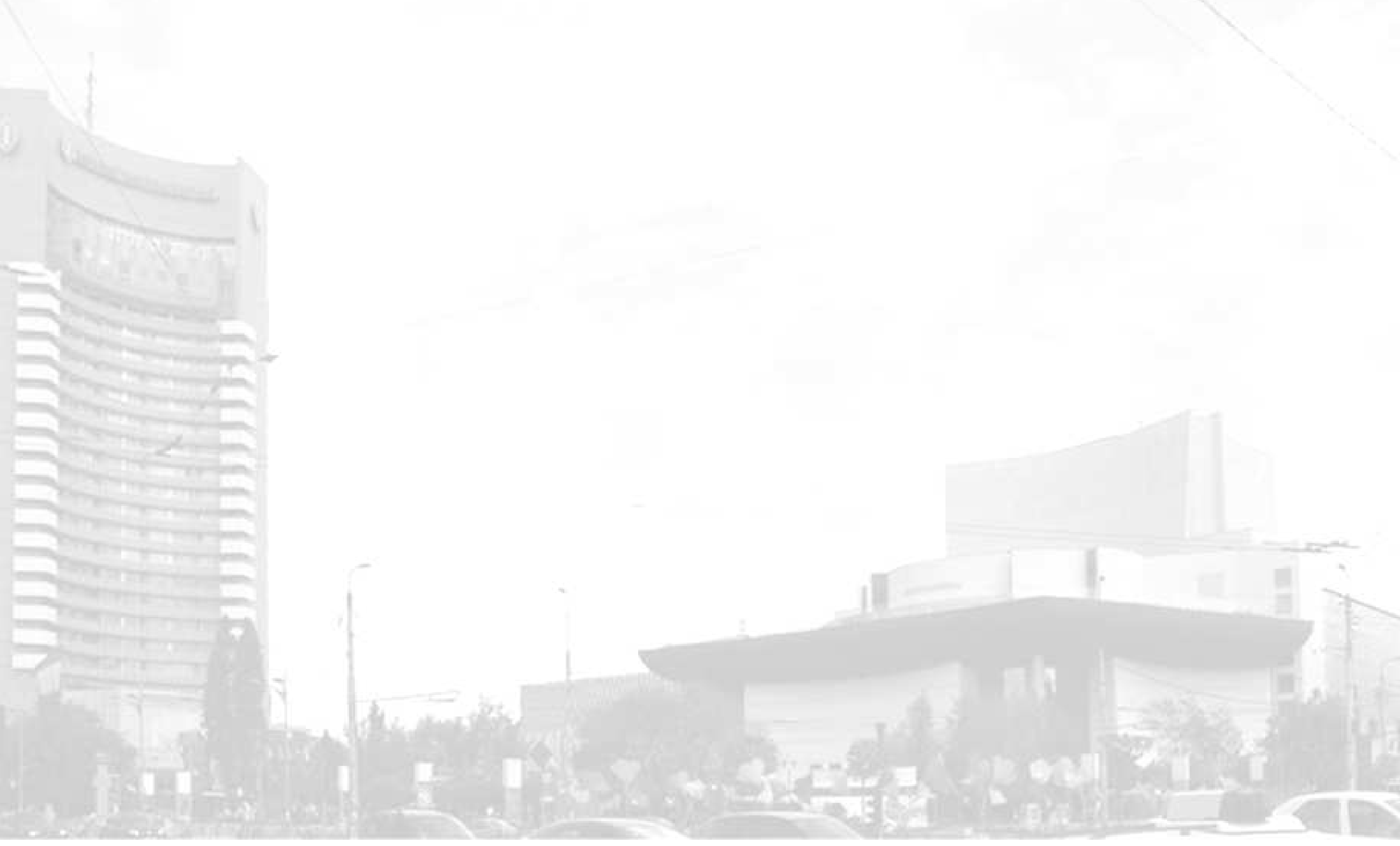

